\title{
Image Analysis of Off-Eutectic Alloys with Lamellar Microstructures ${ }^{1}$
}

\author{
D.F. Susan ${ }^{\mathrm{a}}$, C.V. Robino ${ }^{\mathrm{a}}$, J.N. DuPont ${ }^{\mathrm{b}}$, and M.J. Minicozzi ${ }^{\mathrm{b}}$ \\ ${ }^{a}$ Sandia National Laboratories, Albuquerque, New Mexico \\ ${ }^{\mathrm{b}}$ Lehigh University, Bethlehem, PA
}

This work addresses the quantitative image analysis (QIA) of hypoeutectic microstructures containing primary $\alpha$ phase dendrites and a eutectic mixture of $\alpha$, designated $\alpha_{\text {eut }}$, and a second phase $\beta$. A difficulty in QIA arises because the portion of $\alpha_{\text {eut }}$ that forms on the primary $\alpha\left(\alpha_{\text {pri }}\right)$ dendrites is indistinguishable from the primary phase. It is not revealed by etching, may not have measurable differences in chemistry, and may be on a fine scale which would make chemical analysis attempts difficult. If the $\alpha / \beta$ lamellar eutectic regions are simply "filled in" (closed $\beta$ images) without adding a layer of $\alpha_{\text {eut }}$ (a common oversight in image analysis of eutectic structures), erroneous values may be obtained for the eutectic fraction and the proportions of $\alpha$ and $\beta$ within the eutectic. QIA procedures were developed by Dutta and coworkers[1-3] and Pompe[4] to determine the eutectic fraction while taking into account the portion of $\alpha_{\text {eut }}$ which forms on the $\alpha_{\text {pri }}$ dendrites. The application and modification of one of the procedures, the "chord-size technique", is described in the present work. The modification allows for analysis of more complex eutectic microstructures. The method was applied to Ni-Cr-Mo alloys with Gd additions, the microstructures of which exhibit primary austenite $(\gamma)$ and regions of a eutectic mixture of $\gamma_{\text {eut }}$ and $\mathrm{GdNi}_{5}$ [5].

Figure 1 shows an optical microscopy mosaic image of the alloy microstructure and an individual 500x image from a Ni-Cr-Mo sample with $2.45 \mathrm{wt}$. \% Gd. Other alloys containing 0.46, 1.0, 1.5, and 1.9 wt. \% Gd were also analyzed in this study. The first step in the QIA technique is to measure the $\gamma_{\text {eut }} / \mathrm{GdNi}_{5}$ spacing in the eutectic regions. A set of grid lines is applied to the thresholded image and the grid line lengths (chord sizes) of the $\gamma$ regions are measured automatically. Figure 2 shows histograms of thousands of $\gamma$ chord size measurements collected from three mosaic images. The first peak corresponds to the mean $\gamma$ spacing in the $\gamma_{\text {eut }} / \mathrm{GdNi}_{5}$ eutectic regions, $\bar{L}_{e u t-\gamma}$, and the second peak at approximately $67 \mu \mathrm{m}$ is related to the mean primary $\gamma$ dendrite size, $\bar{L}_{p r i-\gamma}[4]$. From Fig. 2 the $\gamma_{\text {eut }}$ spacing, $\bar{L}_{e u t-\gamma}$, is taken as $\sim 1.15$ microns. The next step is to perform image processing operations to fill in the eutectic regions while also adding a layer of $\gamma_{\text {eut }}$, of thickness $\bar{L}_{e u t-\gamma} / 2$, at the eutectic region $/ \gamma_{\text {pri }}$ interfaces. A number of dilations, $D$, are applied to the binary image followed by a number of erosions, $E$, such that

$$
D-E=\bar{L}_{e u t-\gamma} / 2 L_{p i x},
$$

where $L_{p i x}$ is the pixel size in the image. The number of dilations is increased while maintaining a constant $\mathrm{D}-\mathrm{E}$ value, in this case $\mathrm{D}-\mathrm{E} \approx 6$. The correct number of dilations corresponds to the plateau in Fig. 3, which shows the vol. \% eutectic as the number of dilations is increased. Each dilation fills in small spaces of $\gamma_{\text {eut }}$ within the eutectic and the plateau occurs when all eutectic regions are filled. Additional dilations beyond the plateau then begin to fill in small primary dendrites arms, such as those that were cross-sectioned near their tips. Since the number of erosions is smaller than the number of dilations, the final filled-in eutectic areas display an additional outer layer of $\gamma_{\text {eut, }}$ with pixel width given by the equation above. Finally, this outer layer of $\gamma_{\text {eut }}$ has approximately uniform thickness but modifications of Dutta's procedure can be made to accommodate anomalies in microstructure, such as "partly divorced" eutectic with different lamellar spacings. Figure 4 shows the final digitized microstructure after the chord-size (D-E) procedure is applied and a layer of $\gamma_{\text {eut }}$ is added around all of the eutectic regions. The eutectic structure on the left side of the image shows a 
thicker outer layer of $\gamma_{\text {eut }}$, which serves to maintain the correct ratio of phases within the eutectic in such regions of locally "partly divorced" morphology. This final image was used to obtain the QIA data for volume fraction eutectic as well as the amounts of $\gamma_{\text {eut }}$ and $\mathrm{GdNi}_{5}$ within the eutectic in order to construct a pseudo-binary solidification diagram.

${ }^{1}$ Sandia is a multiprogram laboratory operated by Sandia Corporation, a Lockheed Martin Company, for the US Dept. of Energy's national Nuclear Security Administration under contract DE-AC04-94AL85000.

References

[1] B. Dutta, O. Pompe, and M. Rettenmayr, Mat. Sci. and Tech., (2004), 20, 1011-1018.

[2] B. Dutta and M. Rettenmayr, Mat. Sci. and Tech., (2002), 18, 1428-1434.

[3] B. Dutta and M. Rettenmayr, Mat. Sci. Eng. A, (2000), A283, 218-24.

[4] O. Pompe, Prakt. Metallogr., (1994), 31, 274-83.

[5] C.V. Robino, J.N. DuPont, R.E. Mizia, J.R. Michael, D.B. Williams, and E. Shaber: J. Mat. Eng. Perf., (2003), 12, 206-14.
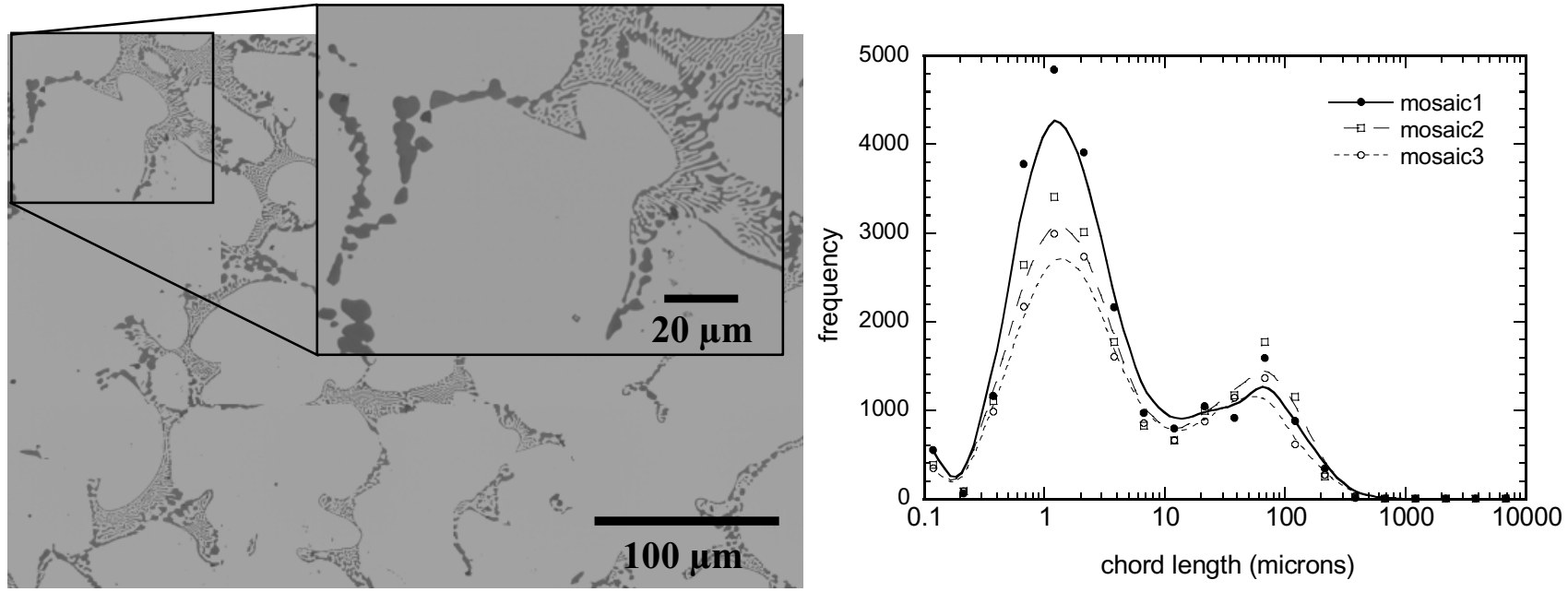

Fig.1. An optical microscopy mosaic and a single 500x photomicrograph of Ni-Cr-Mo- $(+\mathrm{Gd})$ alloy. Fig. 2. Histograms of $\gamma$ phase chord lengths from mosaic images of Ni-Cr-Mo- $(+\mathrm{Gd})$ alloy.
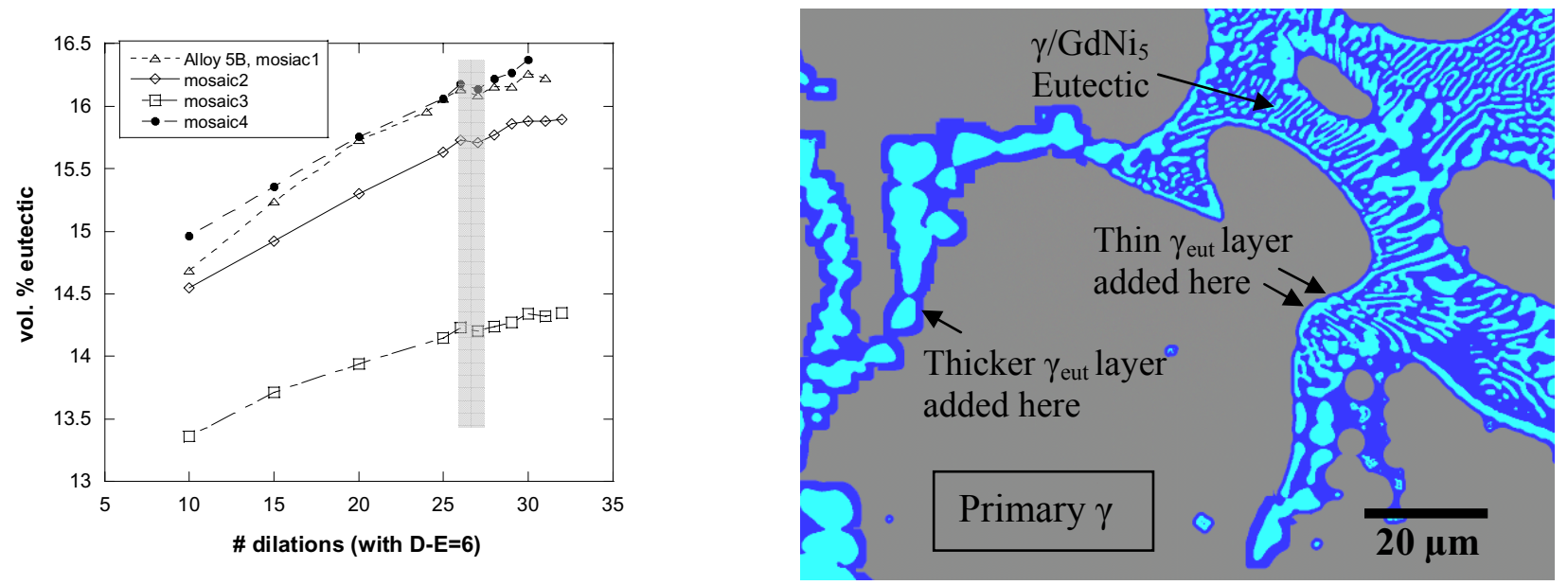

Fig. 3. Plot of vol. \% eutectic vs. the number of dilations (with \# dilations - \# erosions $=6$ ). The shaded region shows the plateau in vol. \% eutectic corresponding to the correct number of dilations. Fig. 4. Processed image showing primary $\gamma, \gamma / \mathrm{GdNi}_{5}$ eutectic, and $\mathrm{y}_{\text {eut }}$ at the eutectic $/ \gamma_{\text {pri }}$ interface. 